\title{
Kararlı Akım Koşullarında Oluşan Hızların Deneysel Olarak Araştırılması
}

\section{Experimental Investigation of Velocities Under Steady State Flow Conditions}

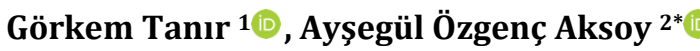 \\ ${ }^{1}$ Dokuz Eylül Üniversitesi Fen Bilimleri Enstitüsü İnşaat Mühendisliği Anabilim Dalı, İzmir, TÜRKiYE \\ ${ }^{2}$ Dokuz Eylül Üniversitesi Mühendislik Fakültesi İnşaat Mühendisliği Bölümü, İzmir, TÜRKIYE \\ Sorumlu Yazar / Corresponding Author*: aysegul.ozgenc@deu.edu.tr \\ Geliş Tarihi / Received: 10.11 .2020 \\ Araştırma Makalesi/Research Article \\ Kabul Tarihi / Accepted: 05.04.2021 \\ DOI:10.21205/deufmd.2021236902 \\ Atıf șekli/How to cite: TANIR G., ÖZGENÇ AKSOY A. (2021). Kararlı Akım Koşullarında Oluşan Hızların Deneysel Olarak Araștırllması. \\ DEUFMD, 23(69), 725-733.
}

Öz

Bu çalışma kapsamında, açık kanalda kararlı (zamanla değişmeyen) akım koşullarında oluşan akım hızlarının deneysel olarak incelenmesi amaçlanmıştır. Bu doğrultuda Dokuz Eylül Üniversitesi İnşaat Mühendisliği Hidrolik Laboratuvarı'nda yer alan açık kanal deney düzeneğinde kararlı akım koşullarında hız ölçümleri yapılmıştır. Ölçümler sırasında ultrasonik yöntemle hız ölçümü yapan UVP (Ultrasonic Velocity Profiler) ve ADV (Acoustic Doppler Velocimeter) cihazları kullanılmıştır. Kararlı akım koşullarında düşey kesit boyunca oluşan hız profilleri UVP cihazı aracıllğ̆ ile elde edilmiştir. Hız profilleri, literatürde önerilen formüller kullanılarak da elde edilmiş olup, deneysel sonuçlarla karşılaștırılmış ve formüllerde yer alan katsayılar için değerler önerilmiştir. Kullanılan formüller içerisinde, Üssel Yasa ve Parabolik Yasa formüllerinin akımın dıș bölgesinde, Logaritmik Yasa formülünün ise akımın iç bölgesinde uyumlu olduğu görülmüştür.

Anahtar Kelimeler: Açık kanal, hız ölçümü, kararlı akım

\begin{abstract}
In this study, velocity distribution in open channel flows was investigated experimentally under steady flow conditions. The experiments were carried out in a channel which was available in the Hydraulics Laboratory of Civil Engineering Department in Dokuz Eylul University. The velocity measurements were conducted by using UVP (Ultrasonic Velocity Profiler) and ADV (Acoustic Doppler Velocimeter) devices. The velocity profiles under steady flow conditions were also obtained by means of UVP device and compared with those computed by using the equations available in the literature. According to the results it was observed that the Power Law and Parabolic Law are compatible with the outer region of the flow and the Logarithmic Law is compatible with the inner region of the flow.

Keywords: Open Channel, velocity measurement, steady flow
\end{abstract}




\section{Giriş}

Doğada oluşan akışkan akımlarının neredeyse tamamı, türbülanslı olarak gerçekleşmektedir. Türbülans olayını olușturan etmenlerin tamamen anlaşılabilmesi, akışkan akımlarında oluşacak hızların, akım şartlarına göre değişiminin detaylı olarak incelenebilmesine bağlıdır. Ayrıca, akarsularda oluşacak akım hızı değerleri ve düșey hız profillerinin doğru bir şekilde öngörülebilmesi, açık kanal hidroliği açısından büyük önem arz etmektedir. $\mathrm{Bu}$ sebeplerden dolayı, akım hızlarının ölçümü, hidromekanik alanında yapılan çalıșmalarda kritik bir rol oynamaktadır.

Vedula ve Achanta [1], boru akımı veya açık kanal akımı gibi farklı akım koșullarında olușan akım bölgelerini incelemişler ve bu bölgelerdeki düşey hız profillerinin, literatürde önerilen Parabolik Yasa ve Logaritmik Yasa formüllerine uyumluluğunu araştırmışlardır. Akımın iç bölgesinde (inner region) Logaritmik, dıș bölgesinde (outer region) ise Parabolik Yasa ile temsil edildiği İkili Yasa (Binary Law) formülünü önermişler ve önerdikleri yasanın geçerliliğini, literatürde yapılmış çalışmalardan elde edilen deneysel verileri kullanarak araştırmışlardır.

Song ve Chiew [2], türbülanslı akımlarda ADV cihazı ile hız ölçümleri yapmıșlardır. Deneyler taban eğimi ayarlanabilir bir laboratuvar kanalında gerçekleștirilmiștir. Kanalın uzunluğu 18 m'dir. Kanal $60 \mathrm{~cm}$ genişliğe ve $80 \mathrm{~cm}$ yüksekliğe sahiptir. Deneylerde $10 \mathrm{MHz}$ frekansa sahip ADV cihazı kullanılmıștır. Deney sonuçlarını kullanarak literatürde yer alan hız dağılımı formüllerine katkıda bulunmuşlardır.

Balachandar, Blakely ve Bugg [3], türbülanslı akıma sahip, sığ açık kanallarda oluşan hız profillerini araştırmışlardır. Sonuç olarak Üssel Yasa formülünde yer alan parametreler için optimum değerler önerilmiştir.

Zrostlík, Bareš, Krupička, Picek ve Matoušek [4], açık kanalda olușan hız profilini ve hızların ölçümünde kullanılan yöntemleri incelemişlerdir. Sedimentli bir kanalda gerçekleştirdikleri deneylerde pitot tübü, Ultrasonic Velocity Profiler (UVP) ve Acoustic Doppler Velocity Profiler (ADVP) olmak üzere üç farklı ölçüm tekniği kullanmışlardır. Sonuç olarak akımda oluşan hız profilinin üst tabakada logaritmik yasa ile ve sediment miktarınca zengin olan alt tabakada doğrusal olarak tanımlanabileceğini öngörmüşlerdir.
Luo, Singh ve Schmidt [5], bir açık kanalda oluşan hız dağılımı için literatürde bulunan deterministik denklemler ile entropi teorisine dayanan hı dağılımı hesaplamalarını karşılaştırmışlardır. Çalışmada Logaritmik Yasa ve Üssel Yasa denklemleri kullanılmıștır. Karşılaștırmalar, literatürde bu alanda yapılmıș çalışmalardan elde edilen deneysel veriler kullanılarak yapılmıștır. Çalıșmanın sonucunda iki farklı yöntemin avantajları ve dezavantajları ortaya konulmuştur.

Açlk kanalda düşey kesit boyunca oluşacak olan hız profilinin belirlenmesi amacı ile farklı çalışmalar yapılmış olup farklı formüller önerilmiştir.

Prandtl [6], hız profilini belirlemek amacıyla așağıda verilen Üssel Yasa (Power Law) formülünü önermiştir.

$$
\frac{u(y)}{u_{\max }}=\left(\frac{y}{h}\right)^{1 / N}
$$

burada h; toplam su derinliği, u_max; düşey kesit boyunca oluşan maksimum hız değeri, y; herhangi bir noktanın kanal tabanına olan mesafesi ve u(y); kanal tabanından y kadar uzaklıkta yer alan noktada oluşan akım hızıdır. $\mathrm{N}$, açık kanalın pürüzlülüğü ve enkesit şekline göre değişen bir katsayıdır. N katsayısı, 4 ile 12 değerleri arasında değișmekte olup literatürde yaygın olarak 6 veya 7 değerleri alınarak kullanılmaktadır.

Nikuradse [7] hız dağılımı üzerine yaptığı deneysel çalışmalarda logaritmik hız dağılımı (logaritmic law) formülünü önermiştir.

$$
\frac{u(y)}{u_{*}}=\frac{1}{K} \ln \left(\frac{y u_{*}}{v}\right)+\mathrm{D}
$$

Formül (2) de yer alan $v$ ve u*, sırası ile akışkanın kinematik viskozitesi ile kayma hızını simgelemektedir. K, Van-Korman sabiti olup 0,41 olarak alınabilir. D ise akım şartlarına göre değişen integrasyon sabitidir. D katsayısının değeri, yapılan çeşitli deneysel çalışmalar ile ortaya konulmuş olup, 5 ile 8,5 değerleri arasında bir değer olarak kabul edilebilmektedir.

Bazin [8], parabolik hız dağılımı yasasını deneysel çalışmalar sonucunda aşağıdaki gibi önermiștir.

$$
\frac{u_{\max }-u(y)}{u_{*}}=\mathrm{C}\left(1-\frac{y}{h}\right)^{2}
$$


Burada C; akım şartlarına göre değişen deneysel bir katsayı olup 5 değerini alabileceği öngörülmüştür.

$\mathrm{Bu}$ çalışma kapsamında, kararlı akım koşullarında akım hızları ADV ve UVP cihazları kullanılarak ölçülmüş ve sonuçlar karşılaştırılmıștır. Ayrıca deneyler sırasında elde edilen düșey hız profilleri, literatürde açlk kanal akımlarında düşey kesiti boyunca oluşacak hız profillerinin belirlenmesi amaciyla verilen formüller kullanılarak elde edilen hız profilleri ile karşılaștırılmıș ve sonuçlar yorumlanmıștır.

\section{Yöntem ve Gerec}

\subsection{Deney düzeneği}

Bu çalışma kapsamında deneyler, Dokuz Eylül Üniversitesi İnşaat Mühendisliği Bölümü Hidrolik Laboratuvarında yer alan açlk kanalda gerçekleştirilmiştir. Açı kanalın genel görüntüsü Şekil 1'de verilmektedir. Kanal, $25 \mathrm{~cm}$ genișliğinde, $27 \mathrm{~cm}$ yüksekliğinde ve $920 \mathrm{~cm}$ uzunluğundadır. Şekil 2'de deney düzeneğinin şematik gösterimi verilmektedir. Heterojen bir enkesite sahip olan kanalın sağ cidarı pleksiglas, tabanı ve sol cidarı metal malzemeden yapılmıștır.

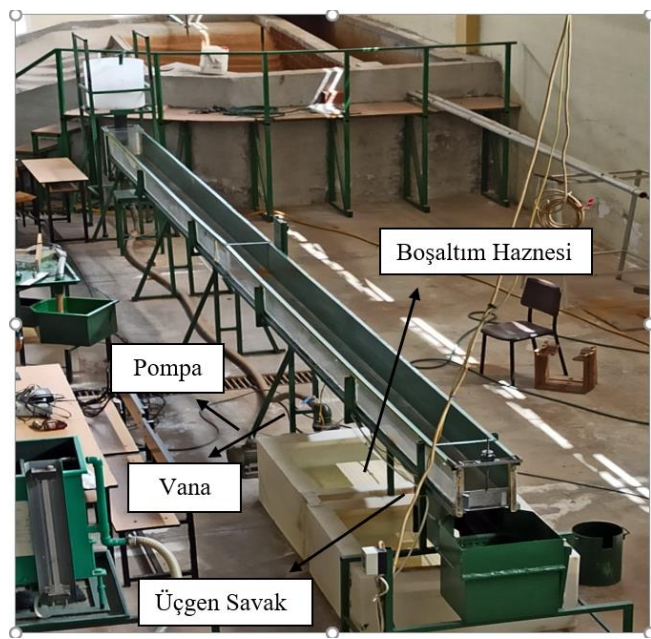

Şekil 1. Deney düzeneği

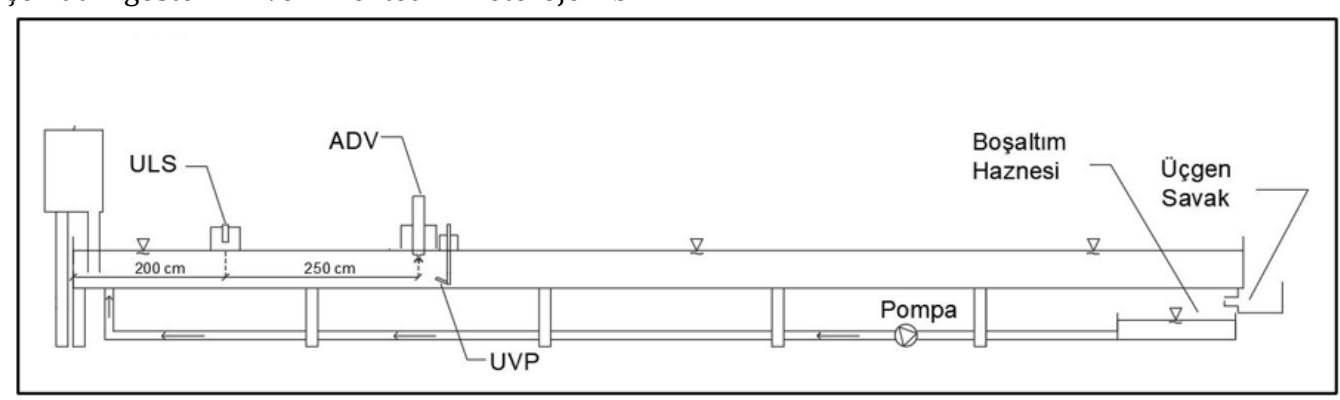

Şekil 2. Deney düzeneğinin șematik gösterimi

\section{2. Ölçüm cihazları}

Deneyler sırasında akım hızlarını ölçmek amacı ile Acoustic Doppler Velocimeter (ADV) ve Ultrasonic Velocity Profiler (UVP) cihazları aynı anda kullanılmıștır. Deneylerde, zamana bağlı su seviye ölçümleri ise Ultralab ULS cihazı ile gerçekleştirilmiştir.

\subsubsection{Ultrasonic Velocity Profiler (UVP) cihazı}

UVP cihazl, Doppler teknolojisini kullanarak ses dalgaları yardımı ile akım hızlarını ölçmektedir. Düşey kesit boyunca hız verilerinin ölçümünü yapabilen UVP cihazı, hiz profillerinin elde edilmesine olanak sağlamaktadır. Cihaz, Şekil 3'te verilen ana kutu ve bu kutuya bağlanan algılayıcılardan oluşmaktadır. Çalışma kapsamında, deneylerde oluşabileceği öngörülen hızlar göz önüne alınmış ve cihazın 2 MHz frekansa sahip algılayıcısı kullanılmıștır. 


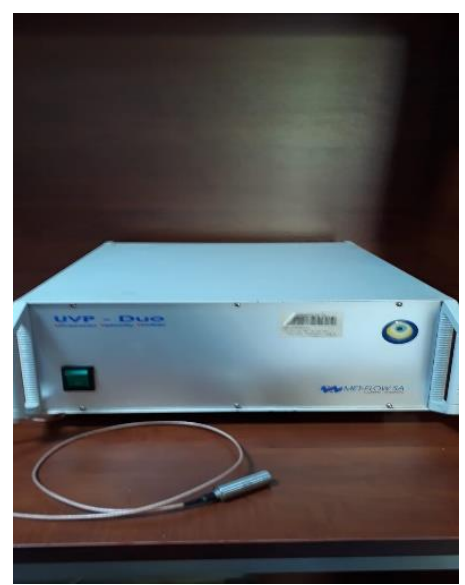

Şekil 3. Ultrasonic Velocity Profiler (UVP)

\subsubsection{Acoustic Doppler Velocimeter (ADV) cihazı}

Acoustic Doppler Velocimeter (ADV), yüksek hassasiyete sahip, noktasal 3 boyutlu akım hızlarının ölçümünü gerçekleştiren bir cihazdır. $\mathrm{Bu}$ çalışmada laboratuvar ölçümlerine uygun olan $16 \mathrm{MHz}$ frekansa sahip MicroADV modeli kullanılmıștır (Şekil 4). Cihaz, sondasından $5 \mathrm{~cm}$ uzaklıktaki akım hızlarını ölçmektedir.

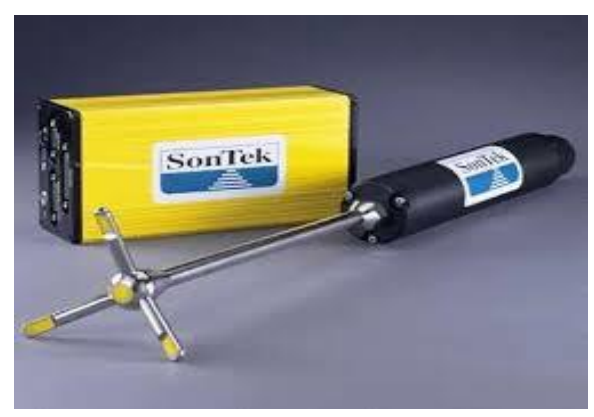

Şekil 4. MicroADV cihazı [9]

\subsubsection{UltraLab ULS cihazı}

Deneylerde belirlenen noktalarda zamana bağlı su seviye değişimleri, UltraLab ULS cihazı kullanılarak ölçülmüştür (Şekil 5).

Cihaza aynı anda dört sensör bağlanabilmekte ve böylece aynı anda dört farklı noktada zamana bağlı su seviye ölçümleri gerçekleştirilebilmektedir. Kararsız akım deneyleri sırasında, taşkın haznesinde bir tane ve kanalda bir tane olmak üzere iki farklı ULS sensörü kullanılmıștır.

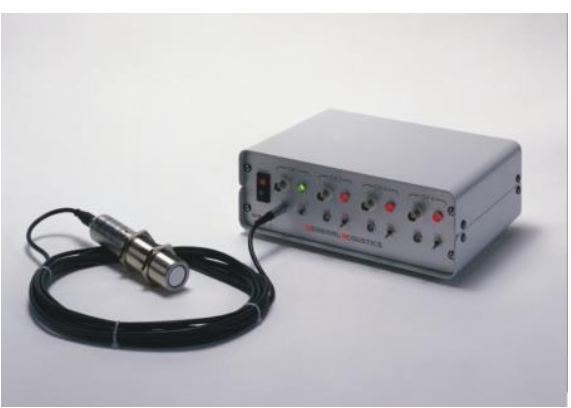

Şekil 5. Ultralab ULS [10]

\subsection{Gerçekleștirilen deneyler}

Gerçekleştirilen deneylerde suyun kanalda yükselebilmesi için kanal mansabına bir eşik yerleştirilmiştir. Debi ölçümleri deney düzeneğinde mevcut olan üçgen savak yardımıyla gerçekleştirilmiştir. Üçgen savak debi formülü:

$$
Q=K \cdot h^{5 / 2}
$$

olup burada $\mathrm{K}$ debi katsayısı, $\mathrm{h}$ ise savak yüküdür. Debi katsayısı (K), deneyler öncesinde kalibre edilerek elde edilmiștir. Kalibrasyon için üçgen savaktan savaklanan suyun debisi ölçekli kap ve kronometre kullanılarak belirlenmiş, üçgen savak yükü ise piyezometre borusu ile ölçülmüștür. Kalibrasyon sonucunda K savak katsayısı 20,2 olarak belirlenmiştir. Savak yükü $\mathrm{cm}$ biriminde formüle konulduğunda debi değeri $\mathrm{cm}^{3} / \mathrm{s}$ cinsinden elde edilmektedir.

ADV ve UVP, kanala Şekil 6 ve Şekil 7'de görülen düzenekler yardımı ile ölçüm noktalarına yerleştirilmiştir. UVP cihazının yerleştirildiği düzenek, algılayıcının akıma 12 derecelik bir açı ile bakacak șekilde yerleştirilmesine olanak sağlamaktadır. Şekil 7'de görüldüğü üzere UVP algılayıcısı kanal tabanına yerleștirilmiş olup ucu yukarı doğru bakmaktadır. K1, K2 ve K3 deneyleri bu şekilde gerçekleștirilmiş olup K4 ve K5 deneylerinde ise kanal tabanına yakın bölgede hızları ölçmek amacıyla UVP algılayıcısı serbest su seviyesinde ve ucu kanal tabanına bakacak şekilde yerleştirilmiştir (Şekil 8). 


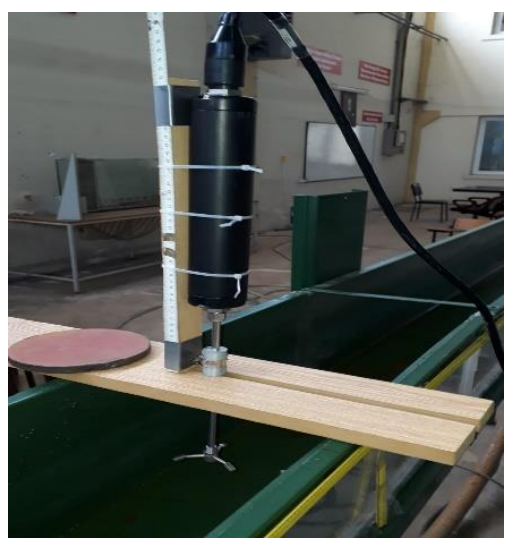

Şekil 6. ADV cihazının yerleșimi

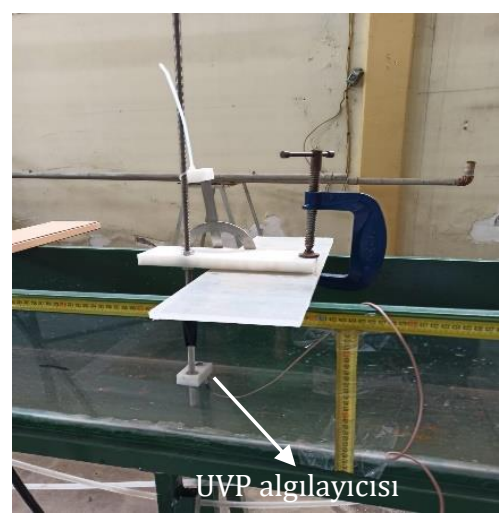

Şekil 7. UVP cihazının yerleșimi

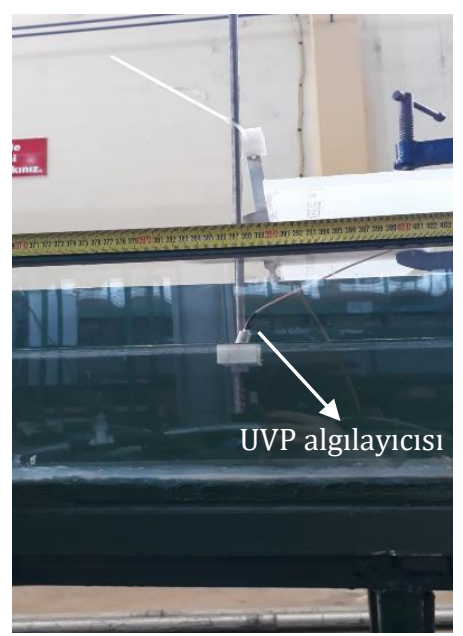

Sekil 8. UVP cihazının serbest su seviyesinden kanal tabanına bakacak şekilde yerleşimi
ADV cihazı, sondasından $5 \mathrm{~cm}$ uzaklıktaki noktada oluşan akım hızlarını ölçmektedir. UVP cihazı ise düşey profil boyunca hız değerlerini ölçmekte olup profil içerisinde yer alan herhangi bir noktada akım hızı değerleri belirlenebilmektedir. Deneylerde cihazlar aralarında $7 \mathrm{~cm}$ olacak şekilde yerleştirilmiş olup noktasal hızları karşılaştırmak amacıyla UVP verilerinde, algılayıcıdan $2 \mathrm{~cm}$ uzaklıktaki noktaya ait ölçümler dikkate alınmıştır. Ölçüm noktasının şematik gösterimi Şekil 9'da verilmiştir.

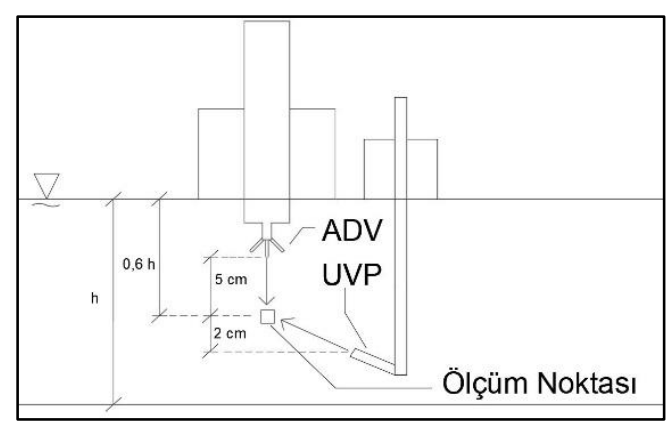

Şekil 9. Ölçüm noktasının șematik gösterimi

Kararlı akım durumunda gerçekleştirilen deney özellikleri Tablo 1'de verilmiştir.

ULS cihazı ile ölçülen derinlik yardımıyla hesaplanan akım alanı ve üçgen savak ile belirlenen debi değeri süreklilik denkleminde yerine konularak kesitsel ortalama hız değeri hesaplanmıștır. 
DEÜ FMD 23(69), 725-733, 2021

Tablo 1. Kararlı akım deneylerinin özellikleri.

\begin{tabular}{lllll}
\hline Deney & $\begin{array}{l}\text { SuDerinliği } \\
(\mathrm{cm})\end{array}$ & $\begin{array}{l}\text { Debi } \\
\left(\mathrm{cm}^{3} / \mathrm{s}\right)\end{array}$ & $\begin{array}{l}\text { UVPalgılayıcısının } \\
\text { yönü }\end{array}$ & $\begin{array}{l}\text { Kesitsel } \\
\text { Ortalama } \\
\text { Hız } \\
(\mathrm{cm} / \mathrm{s})\end{array}$ \\
\hline K1 & 13,5 & 1781 & Yukarı & 5,28 \\
K2 & 13,8 & 2012 & Yukarı & 5,83 \\
K3 & 14,3 & 2175 & Yukarı & 6,09 \\
K4 & 14,4 & 2455 & Aşă̆ı & 6,82 \\
K5 & 14,5 & 2809 & Așağı & 7,75 \\
\hline
\end{tabular}

\section{Deneysel Sonuçlar}

\subsection{Zamana Bağlı Noktasal Hız Ölçümleri}

ADV ve UVP cihazlarıyla elde edilen hız ölçüm değerlerinde mevcut olabilecek aykırı verileri ayıklamak amaciyla MATLAB programinda mevcut olan "rmoutliers" fonksiyonunun medyan yöntemi kullanılmıștır.

Şekil 10, Şekil 11 ve Şekil 12'de K1, K2 ve K3 deneyleri sirasinda hem ADV hem de UVP cihazları ile ölçülen zamana bağlı hız grafikleri verilmektedir. Deneylerde ADV ve UVP hız cihazları aracılığı ile ölçülen zamana bağlı hız değerlerinin ortalamaları alınarak, kararlı akımlara ait ortalama hız değerleri elde edilmiștir.

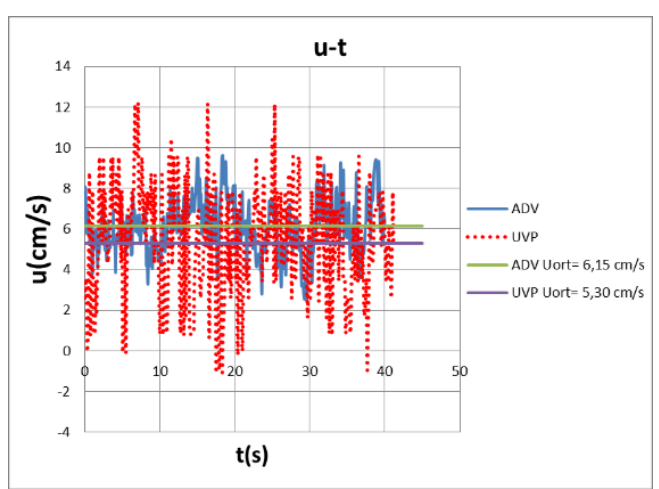

Şekil 10. K1 deneyi için ADV ve UVP cihazları ile elde edilen hız-zaman serisi

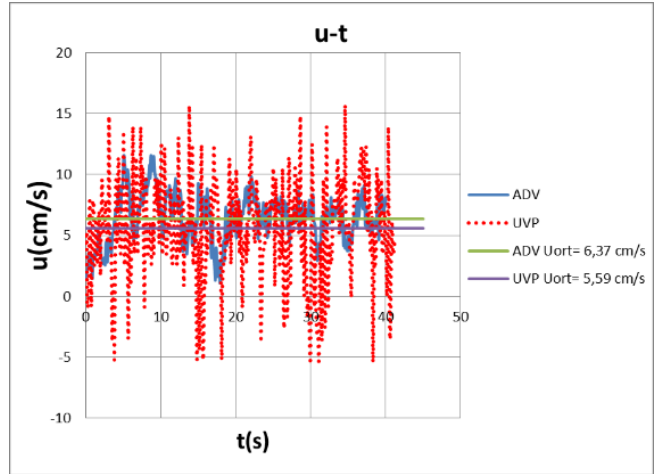

Şekil 11. K2 deneyi için ADV ve UVP cihazları ile elde edilen hız-zaman serisi

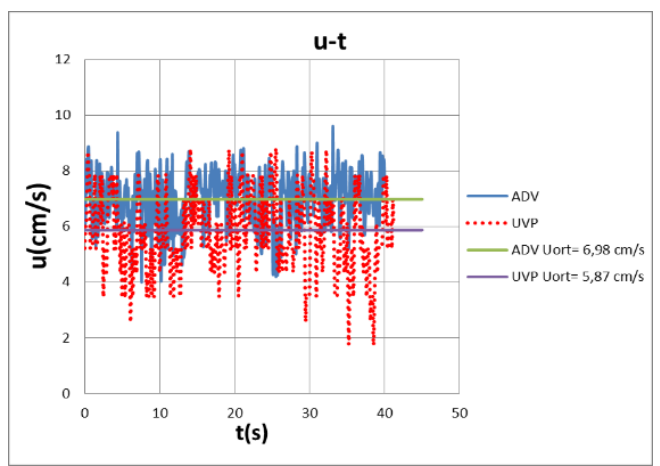

Şekil 12. K3 deneyi için ADV ve UVP cihazları ile elde edilen hız-zaman serisi

Tablo 2'de K1, K2 ve K3 deneylerine ait ölçülen ve hesaplanan ortalama hı değerleri verilmektedir. Hesaplanan kesitsel ortalama hız değerleri $\mathrm{Q}=\mathrm{AV}$ denklemi kullanılarak elde edilmiştir. 
DEÜ FMD 23(69), 725-733, 2021

Tablo 2. Kararlı akım deneyleri akım hızları.

\begin{tabular}{lllc}
\hline Deney No & ADV (cm/s) & $\begin{array}{l}\text { UVP } \\
(\mathrm{cm} / \mathrm{s})\end{array}$ & $\begin{array}{l}\text { HESAP } \\
(\mathrm{cm} / \mathrm{s})\end{array}$ \\
\hline K1 & 6,15 & 5,30 & 5,28 \\
K2 & 6,37 & 5,59 & 5,83 \\
K3 & 6,98 & 5,87 & 6,09 \\
\hline
\end{tabular}

Kararlı akım deneylerinden elde edilen hızzaman serilerinden görülebileceği üzere, cihazlardan elde edilen ortalama akım hızları, birbirlerine yakın değerlerde olup süreklilik denklemi ile hesaplanan kesitsel ortalama hız değerleri ile de uyumlu olduğu görülmektedir.

\subsection{Düşey Kesit Boyunca Ölçülen Hız Profilleri}

Deneyler sırasında düşey kesit boyunca oluşan hız profilleri, UVP cihazı yardımı ile belirlenmiștir. Deneyler sonucu elde edilen veriler, literatürde açık kanal akımında oluşan hız profillerini belirlemek amacı ile önerilen formüllerin sonuçları ile karşılaştırılmıștır.

K1, K2 ve K3 deneylerinde oluşan düşey hız profillerinin, formüller aracılığ ile elde edilen hız profilleri ile karșılaștırmaları Șekil 13, 14 ve Şekil 15'te verilmektedir.

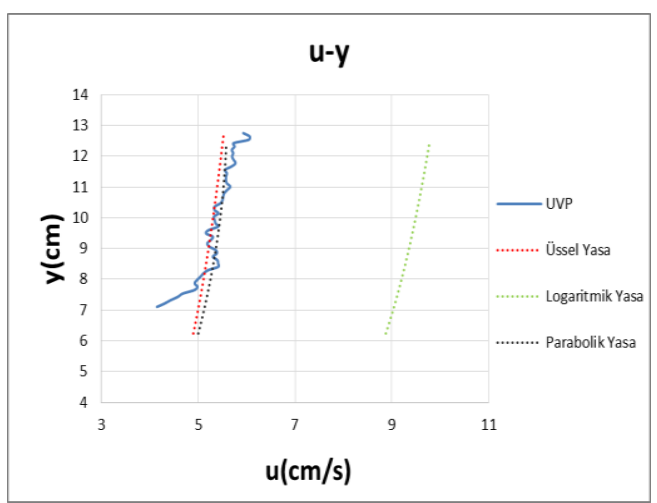

Şekil 13. K1 deneyi için elde edilen hız profili ile farklı yasalar kullanılarak hesaplanan hız profili

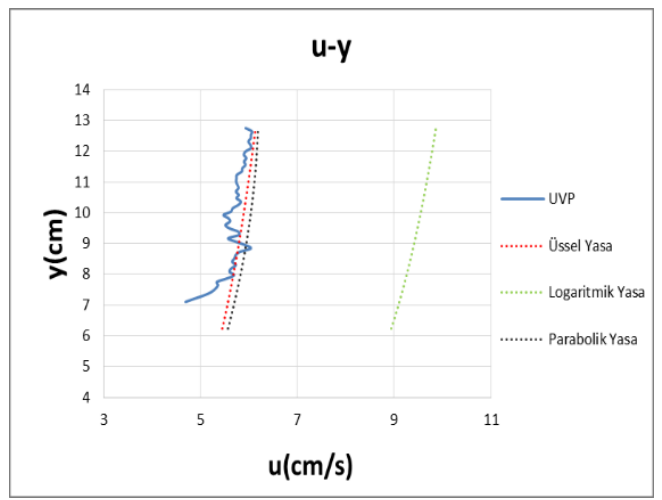

Şekil 14. K2 deneyi için elde edilen hız profili ile farklı yasalar kullanılarak hesaplanan hız profili

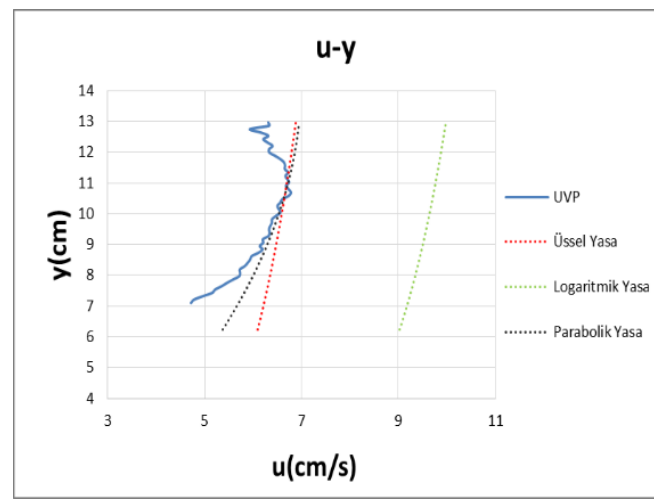

Şekil 15. K3 deneyi için elde edilen hız profili ile farklı yasalar kullanılarak hesaplanan hız profili

Yukarıda verilen düşey hız profili grafiklerinden de görülebileceği üzere Üssel ve Parabolik Yasa kullanılarak elde edilen profiller deney sonuçlarıyla daha uyumlu olup Logaritmik yasa ile elde edilen hız profilleri deneysel verilerle uyuşmamaktadır. $\mathrm{Bu}$ uyuşmazlığın sebebi Logaritmik yasanın daha çok tabana yakın bölgelerde meydana gelen hız profilleri ile daha uyumlu olmasidır. K1, K2 ve K3 nolu deneylerde UVP algılayıcısı kanal tabanından $5 \mathrm{~cm}$ yüksekliğe yerleștirilmiş olup kanal tabanından $0,2 \mathrm{~h}$ yüksekliğe kadar olan kısmını temsil eden iç bölgede oluşan düşey hı profili incelenememiştir. Bu sebeple K4 ve K5 deneyleri gerçekleștirilmiștir. Bu deneyler sırasında UVP algılayıcısı, serbest su seviyesi hizasında ve kanal tabanına bakacak şekilde yerleştirilmiş ve böylece düșey kesitin tamamında oluşan hız 
DEÜ FMD 23(69), 725-733, 2021

profili incelenebilmiștir. K4 ve K5 deneylerinden elde edilen düșey hız profillerinin, İkili Yasa ile elde edilen hız profilleri ile karşılaștırmaları Şekil 16 ve Şekil 17'de verilmiştir. İkili Yasa, akımın iç bölgesinde (inner region) Logaritmik, dış bölgesinde (outer region) ise Parabolik Yasa ile temsil edildiği yasadır.

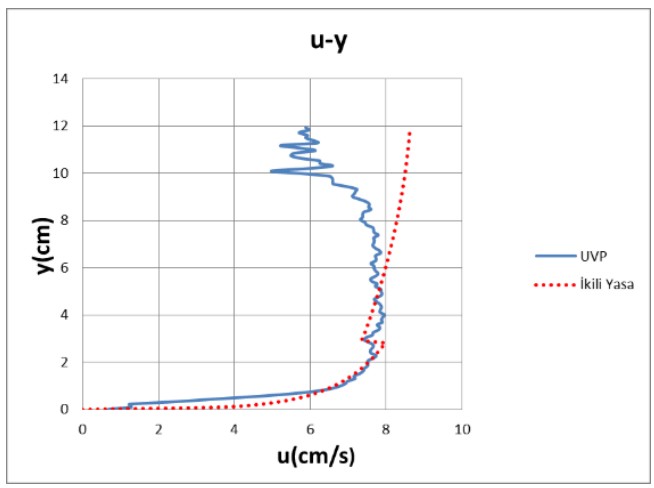

Şekil 16. K4 deneyi için elde edilen hız profili ile İkili Yasa kullanılarak hesaplanan hız profili

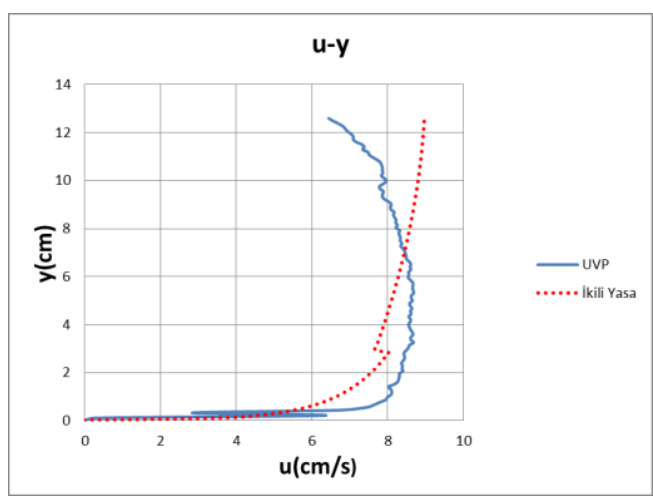

Sekil 17. K5 deneyi için elde edilen hız profili ile İkili Yasa kullanılarak hesaplanan hız profili

$\mathrm{Bu}$ grafiklerden de görüldügü gibi açık kanal akımlarında hız profili belirlenirken kanal tabanına yakın olan iç bölgede logaritmik yasa dış bölgede ise parabolik yasanın uygulanması uygun olmaktadır.

\section{Tartışma ve Sonuç}

$\mathrm{Bu}$ çalıșma kapsamında, açık kanalda kararlı akım koşullarında oluşan akım hızları incelenmiştir. Deneyler, Dokuz Eylül Üniversitesi İnşaat Mühendisliği Hidrolik
Laboratuvarı'nda bulunan açık kanalda gerçekleştirilmiştir. Deneyler sırasında noktasal akım hızlarının zamana bağlı değișimi ve hız profilleri UVP ve ADV cihazları aracılığı ölçülmüştür. Deneylerden elde edilmiş olan düşey hız profilleri üzerine yapılan incelemeler, Üssel Yasa ve Parabolik Yasa formüllerinin, akımın $0,2 \mathrm{~h}$ yüksekliğine kadar olan kısmını temsil eden dış bölgesinde olumlu sonuçlar verdiğini göstermektedir. Ancak Logaritmik Yasa formülü ile elde edilen düșey hız profillerinin, dış bölgede deneysel sonuçlar ile uyumlu olmadığı görülmüştür. Düşey hız profillerinin, akımın iç bölgesinde Logaritmik, dış bölgesinde ise Parabolik Yasa ile temsil edildiği İkili Yasa ise deneysel olarak elde edilen profiller ile yakın sonuçlar vermiş olup, Logaritmik Yasanın akımın iç bölgesine, Parabolik Yasanın ise akımın dış bölgesinde uyumlu sonuçlar verdiği gözlenmiștir. Her bir düşey hız profili formülüne ait katsayılar, deneysel sonuçlar kullanılarak optimize edilmiştir. $\mathrm{Bu}$ doğrultuda $\mathrm{N}$ (Üssel Yasa), C (Parabolik Yasa) ve D (Logaritmik Yasa) katsayıları için sırasıyla 6, 4 ve 8,5 değerlerinin kullanılması uygun bulunmuştur.

İkili yasa ve sayısal model aracılığıyla elde edilen hız profillerinin deneysel sonuçlar ile uyumunu gösteren saçılma diyagramlarıda incelenmiş olup Şekil 18 ve 19'da verilmektedir. Ölçülen hız profilleri ile hesaplanan hız profilleri arasındaki regresyonun incelenmesi amaciyla $\mathrm{R}^{2}$ (Belirleme Katsayısı) ve SI (Saçılma İndisi) değerleri hesaplanmıștır. Bu değerler grafikler üzerinde görülebilmektedir. $\mathrm{R}^{2}$ ve $\mathrm{SI}$ değerlerinin hesaplanmasında kullanılan formüller; Denklem $5,6,7,8$ ve 9'da verilmiştir.

$$
\begin{aligned}
& S S E=\sum_{i=1}^{n}\left(Y_{\mathrm{I}}-Y_{\mathrm{I}}^{\prime}\right)^{2} \\
& S S R=\sum_{i=1}^{n}\left(Y_{\mathrm{I}}^{\prime}-Y_{\text {ort }}\right)^{2} \\
& R^{2}=\frac{S S R}{S S E+S S R} \\
& R M S E=\sqrt{\frac{S S E}{n}} \\
& S I=\frac{R M S E}{Y_{\text {ort }}}
\end{aligned}
$$


DEÜ FMD 23(69), 725-733, 2021

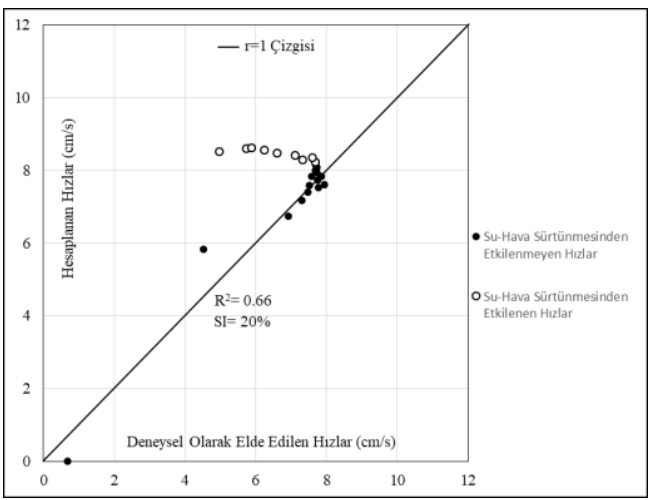

Şekil 18. K4 deneyi için gerçekleștirilen deneylerde düşey kesit boyunca elde edilen akım hızlarının İkili Yasa formülü aracılığıyla elde edilen akım hızları ile saçılma diyagramı

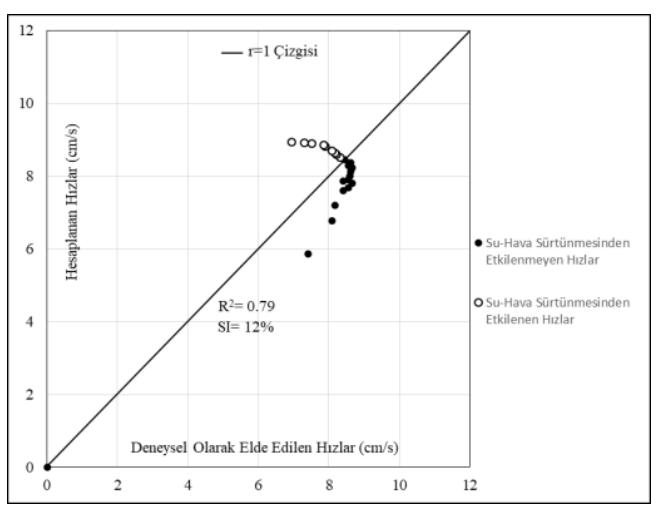

Şekil 19. K5 deneyi için gerçekleştirilen deneylerde düșey kesit boyunca elde edilen akım hızlarının İkili Yasa formülü aracılığıyla elde edilen akım hızları ile saçılma diyagramı

Grafiklerden görüldüğü üzere deneyler sırasında ölçülen hız profilleri ve İkili Yasa formülü aracılı̆̆ uyumludur. Ancak serbest su seviyesine yaklaştıkça, İkili Yasa ile elde edilen akım hızları, deneysel sonuçlardan uzaklaşmaktadır. Saçılma diyagramlarına bakıldığında, su ile hava arasındaki sürtünmenin akımı etkilediği bölgelerde, deneysel veriler ile hesaplanan verilerin $\quad r=1$ doğrusundan uzaklaştığ görülebilmektedir. Bu durum İkili Yasa formülü ile elde edilmiş olan çözümlerde, su ile hava arasındaki sürtünmenin modellenemediğini göstermektedir.

\section{Teşekkür}

$\mathrm{Bu}$ çalıșmada kullanılan ölçüm cihazları TÜBİTAK 106 M274 ve 116 M237 nolu projeler kapsamında sağlanan maddi desteklerle alınmış olup TÜBİTAK'a teșekkürlerimizi sunarız.

\section{Kaynakça}

[1] Vedula, S. ve Achanta, R. R. 1985. Bed shear from velocity profiles: A new approach. Journal of Hydraulic Engineering, 111(1), 131-143.

[2] Song, T. ve Chiew, Y. M. 2001. Turbulence measurement in nonuniform open-channel flow using Acoustic Doppler Velocimeter (ADV). Journal of Engineering Mechanics, 127(3), 219-232.

[3] Balachandar, R., Blakely, D. ve Bugg, J. 2002. Friction velocity and power law velocity profile in smooth and rough shallow open channel flows. Canadian Journal of Civil Engineering, 29(2), 256-266.

[4] Zrostlík, Š., Bareš, V., Krupička, J., Picek, T. ve Matoušek, V. 2015. One-dimensional velocity profiles in open-channel flow with intense transport of coarse sediment. EPJ Web of Conferences, 92, 02120.

[5] Luo, H., Singh, V. ve Schmidt, A. 2018. Comparative study of 1D entropy-based and conventional deterministic velocity distribution equations for open channel flows. Journal of Hydrology, 563, 679693.

[6] Prandtl, L. 1925. 7. Bericht über Untersuchungen zur ausgebildeten Turbulenz. ZAMM-Journal of Applied Mathematics and Mechanics/Zeitschrift für Angewandte Mathematik und Mechanik, 5(2), 136139.

[7] Nikuradse, J. 1933. Stromungsgesetze in rauhen Rohren. VDI-Forschungsheft, 361, 1.

[8] Bazin, H. E. 1865. Recherches hydrauliques, memoires presentes par divers savants. Science Mathematiques et Physiques, Series, 2.

[9] Sontek 2007. HorizonADV User Guide.

[10] General Acoustics 2007. Ultralab ULS User Manual. 